\title{
A study of caesarean sections in referred cases
}

\author{
Devanshi Shah*, Arti Patel, Maitry Mandaliya
}

Department of Obstetrics and Gynaecology, SCL Hospital, NHL Municipal Medical College, Gujarat, India

Received: 27 October 2021

Revised: 06 December 2021

Accepted: 07 December 2021

\author{
*Correspondence: \\ Dr. Devanshi Shah, \\ E-mail: devanshishah6.ds@gmail.com
}

Copyright: (c) the author(s), publisher and licensee Medip Academy. This is an open-access article distributed under the terms of the Creative Commons Attribution Non-Commercial License, which permits unrestricted non-commercial use, distribution, and reproduction in any medium, provided the original work is properly cited.

\begin{abstract}
Background: Referral is a coordinated movement of healthcare seekers through the health system to reach a high level of care in a small and often fatal window of time. Even physiological processes like pregnancy and childbirth are not free of complications. The purpose of this study is to understand maternal and foetal outcome in caesarean sections in referred cases.

Methods: A prospective study was carried out in the OBGY department of SMT.SCL HOSPITAL, NHL Municipal medical college from April 2020 to April 2021. All referred antenatal and intranatal patients to our tertiary care centre with $>20$ weeks of gestation who underwent caesarean section with referral note.

Results: A total $64 \%$ patients were referred from community health center. $63.5 \%$ patients were referred due to lack of high-risk management services. 211 patients underwent caesarean section while 69 patients had normal vaginal delivery. Difficulty in delivery of the baby was encountered in 53\% of cases due to deep engagement of the fetal head. Major cause of admission in NICU was sepsis (38.6\%) followed by prematurity $(23.8 \%)$.

Conclusions: Cesarean section is one of the quickest and most efficient method in the delivery of the baby and thus should in considered in patients in critical situations. The millennium development goals defined by united nation includes one goal (MDG 5) towards improving maternal health which still remains a challenge. Thus, improving knowledge of women regarding good antenatal care and strengthening referral services will play a big role in this.
\end{abstract}

Keywords: Hypertensive disorders of pregnancy, Referral, Community health center, Previous caesarean section

\section{INTRODUCTION}

Pregnancy and childbirth though being physiological processes are not free of complications and risks. ${ }^{1}$ Routine antenatal care helps in early detection of such risks and also access to available skilled care. Lack of awareness regarding proper antenatal care leads to late referrals leading to increase in maternal morbidity and mortality.

Majority of the maternal deaths are avoidable when proper and timely access of healthcare is available. Strong referral system plays an important role in this.
High risk pregnancies require prompt decision making and proper intrapartum management.

Referral of such kind of mothers for better pregnancy and childbirth can contribute a lot for safe feto maternal outcome. Timely intervention in the form of cesarean section in such patients reduces the maternal and fetal risk to great extent and can get proper care.

Efficient and prompt treatment helps in reduction of complications and especially in high risk referred patients, but delays at different tiers leads to worsening of the situation. Prevention of maternal mortality (PMM) 
network study has proposed a "three delays model" for referrals in obstetrics and gynecology emergencies. ${ }^{2}$

The availability of EMOC (emergency obstetric care) is considered to be an indicator on how well a health system is able to manage conditions leading to acute maternal mortality and morbidity. ${ }^{3,4}$ EMOC refers to elements of obstetric care needed for management of complications during pregnancy, delivery and postpartum period. Aim of current study is to evaluate the maternal and fetal outcome in such referred cases at our tertiary hospital.

\section{METHODS}

A prospective observational study was carried out in the obstetrics and gynecological department of SMT. SCL hospital, SMT NHL Municipal Medical College from April 2020 to April 2021.

\section{Inclusion criteria}

All referred antenatal and intranatal patients to our tertiary care center with $>20$ weeks of gestation who underwent cesarean section with referral note were included in the study.

\section{Exclusion criteria}

All referred cases of $<20$ weeks of gestation, postpartum referrals, patients who didn't give permission were excluded from the study.

\section{Procedure}

All the details of the included cases were noted including (obstetric score, details of antenatal period as per the predetermined proforma. All routine investigations were carried out like complete blood count, blood group, ultrasound and COVID-19 RTPCR/Rapid antigen test. All the details were tabulated and analyzed. SPSS version 27 was used for the statistical analysis of the data.

\section{RESULTS}

A total of 280 patients were included during the study period at out tertiary care center from April 2020 to April 2021. Out of these 10 patients were detected covid-19 positive during our study period. Since our tertiary care hospital was declared as a non-COVID hospital, mandatory RTPCR/rapid test was carried out of all patients. In our study the majority of the patients belong to the age group of 20-30 years and are gravida 2 or 3 patients showing that maximum parity is in the reproductive age group of the patients. Most of the referred patients were from $\mathrm{CHC}$ followed by various government hospitals. Maximum patients were referred from community health centre $(65 \%)$ ).Most of the patients those were referred were within $50 \mathrm{kms}$ of distance of our tertiary care hospital. Patients were referred to higher tertiary center majorly due to lack of high-risk management services followed by problems with NICU for further management of neonates. High risk patients needing intensive care and equipment were referred to the higher centers for further management.

Table 1: Parity wise age distribution of referred cases.

\begin{tabular}{|llll|}
\hline Gravidity & $\begin{array}{l}<0 \text { years } \\
\text { N }(\boldsymbol{\%})\end{array}$ & $\begin{array}{l}\text { 20-30 years } \\
\mathbf{N}(\boldsymbol{\%})\end{array}$ & $\begin{array}{l}>30 \text { years } \\
\mathbf{N}(\boldsymbol{\%})\end{array}$ \\
\hline Primi & $05(100)$ & $100(37.5)$ & $001(11.1)$ \\
\hline $\mathbf{2 - 3}$ & $00(0)$ & $146(54.8)$ & $002(22.2)$ \\
\hline$>\mathbf{3}$ & $00(0)$ & $020(7.5)$ & $006(66.6)$ \\
\hline Total & $05(1.7)$ & $266(95)$ & $009(3.2)$ \\
\hline
\end{tabular}

Note: Chi square $=44.52 ; \mathrm{P}$ value $=0.000$

Table 2: Distribution according to referral centres.

\begin{tabular}{|llll|}
\hline $\begin{array}{l}\text { Place of } \\
\text { referrals }\end{array}$ & $\mathbf{N}(\%)$ & $\begin{array}{l}\text { Normal } \\
\text { delivery }\end{array}$ & $\begin{array}{l}\text { Casearean } \\
\text { section }\end{array}$ \\
\hline $\begin{array}{l}\text { Community } \\
\text { health centres }\end{array}$ & $\begin{array}{l}160 \\
(64.2)\end{array}$ & 40 & 120 \\
\hline $\begin{array}{l}\text { Primary } \\
\text { health centres }\end{array}$ & $\begin{array}{l}002 \\
(0.7)\end{array}$ & 1 & 001 \\
\hline $\begin{array}{l}\text { Private } \\
\text { hospital }\end{array}$ & $\begin{array}{l}040 \\
(10.7)\end{array}$ & 14 & 026 \\
\hline $\begin{array}{l}\text { Other } \\
\text { hospitals* }\end{array}$ & $\begin{array}{l}078 \\
(24.2)\end{array}$ & 14 & 064 \\
\hline Total & 280 & 69 & 211 \\
\hline
\end{tabular}

Note: *Government corporation hospitals and associated hospitals; $\mathrm{p}<0.00001$.

Table 3: Distribution according to causes of referral.

\begin{tabular}{|l|l|}
\hline Causes of referral & N \\
\hline $\begin{array}{l}\text { Lack of high-risk management } \\
\text { services (OBSICU) }\end{array}$ & $178(63.5)$ \\
\hline Non availability of NICU & $56(20)$ \\
\hline $\begin{array}{l}\text { Non availability of blood and blood } \\
\text { products }\end{array}$ & $34(12.1)$ \\
\hline Lack of financial support & $12(4.2)$ \\
\hline Total & 280 \\
\hline
\end{tabular}

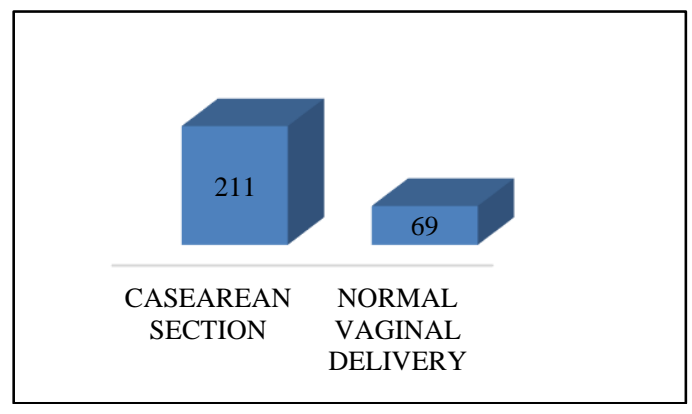

Figure 1: Mode of delivery in referral cases.

This bar chart depicts the mode of delivery in referred cases showing that most of the referred patients (75.3\%) had undergone cesarean section. Previous caesarean 
section was the leading cause for referral followed by hypertensive disorders of pregnancy, obstructed labor, prolonged prom. Intraoperative as well as post operative difficulties were taken into consideration. Difficulty in delivery of the baby was encountered in $53 \%$ of cases due to deep engagement of the fetal head. Total live births in this study were $278(99 \%)$ in which 88 babies were admitted in NICU. Major cause of admission in NICU was sepsis $(38.6 \%)$ followed by prematurity $(23.8 \%)$. Birth asphyxia was observed in neonates where difficult delivery of fetus was noted leading to increase stress on the neonate.

Table 4: Indications of caesarean section in referred cases.

\begin{tabular}{|ll|}
\hline Indications & N \\
\hline PREVCS/PREV2CS & $64(30.3)$ \\
\hline $\begin{array}{l}\text { Hypertensive disorders of } \\
\text { pregnancy }\end{array}$ & $48(22.7)$ \\
\hline Obstructed labour & $28(13.2)$ \\
\hline Prolonged PROM & $22(10.4)$ \\
\hline MSL+FD & $20(9.4)$ \\
\hline Severe oligohydraminos & $14(6.6)$ \\
\hline $\begin{array}{l}\text { Abnormal presentation (breech, } \\
\text { oblique LIE, hand presentation, } \\
\text { cord prolapse) }\end{array}$ & $12(4.7)$ \\
\hline $\begin{array}{l}\text { Others (APH, suspected/confirmed } \\
\text { COVID-19 infection) }\end{array}$ & $10(2.35)$ \\
\hline Total & 218 \\
\hline
\end{tabular}

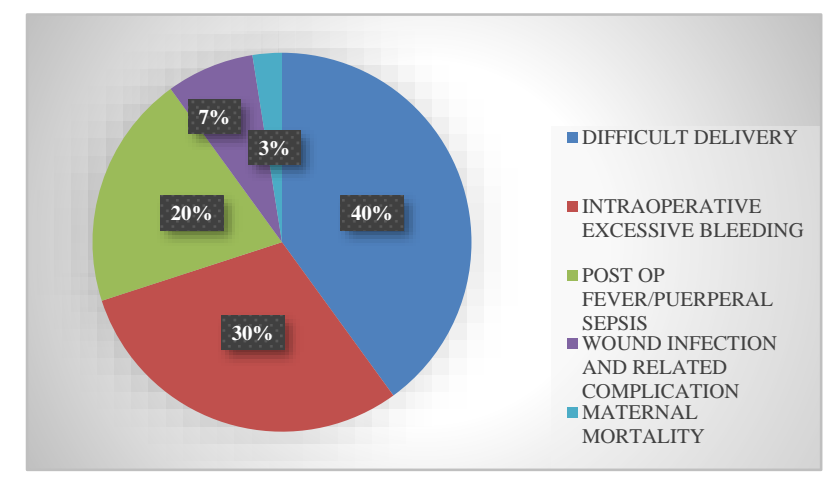

Figure 2: Maternal outcome in referred cases.

\section{DISCUSSION}

In present study, majority of the patients belonged to the age group of $20-35$ years $(95 \%)$ which is similar to the results observed in the study Banu et al (74\%) as well as in the study Goswami et al showing that maximum parity is seen during the reproductive age group of females. ${ }^{5-8}$ In our study $95 \%$ patients were gravida 2 and 3 patients while in Mahendra et al $48 \%$ patients were primigravida patients. ${ }^{1}$ Study by Patel et al and Sable and Patankar showed that maximum referrals were from community health centres followed by other government and corporation hospitals and private hospitals. ${ }^{6,7}$ Delay in referrals from the periphery centre were mostly due to delay in decision making by the family or delay in arrangement of transport. Suspected COVID-19 patients were also referred from CHC'S due to lack of training in handling COVID-19 patients as well as lack of infrastructure. Although private hospitals provide maximum comfort as well as skilled care, lack of assistance or a skilled team in high-risk cases as well as monetary issues faced were the major reasons for referrals.

Table 5: Fetal outcome in referred cases.

\begin{tabular}{|c|c|c|c|c|}
\hline \multirow{6}{*}{$\begin{array}{l}\text { NICU } \\
\text { admission }\end{array}$} & $\begin{array}{l}\text { Perinatal } \\
\text { outcome }\end{array}$ & $\mathbf{N}(\%)$ & ND & CS \\
\hline & Sepsis & $\begin{array}{l}34 \\
(38.6)\end{array}$ & 14 & 20 \\
\hline & Prematurity & $\begin{array}{l}21 \\
(23.8)\end{array}$ & 10 & 11 \\
\hline & Mas & $\begin{array}{l}11 \\
(0.1)\end{array}$ & 05 & 06 \\
\hline & Birth asphyxia & $\begin{array}{l}12 \\
(0.1)\end{array}$ & 05 & 07 \\
\hline & $\begin{array}{l}\text { Apgar score }<5 \\
\text { min }\end{array}$ & $\begin{array}{l}10 \\
(0.1)\end{array}$ & 05 & 05 \\
\hline Still birth & 002 & & & \\
\hline
\end{tabular}

Note: $\mathrm{Ci}$ square $=5.17 ; \mathrm{p}$ value $<0.0001$.

In the study Sharma et al $49 \%$ cases were referred due to lack of specialty services. ${ }^{7-12}$ Lack of basic equipment and knowledge leading to increased referral rates was also summarized by Rao et al. ${ }^{13}$ Increasing the availability of specialty services in periphery will lead to decrease in burden of tertiary hospitals as well as maternal morbidity and mortality. In spite of tremendous efforts made by government in increasing the facilities at basal levels, still the misuse of the funds and lack of proper implementation of maternal healthcare beneficiary programmes and lack of positive attitude and inclination of healthcare professionals towards maternal care have resulted in lack of achievement of desired downfall of referral rates. $45 \%$ cases underwent cesarean section in Goswami et al whereas Gupta observed that $69 \%$ underwent vaginal delivery. ${ }^{11,12}$ In our study, cesarean section rate is substantially high in referred cases due to patients being referred at such time where attempt to conduct vaginal delivery will be hazardous to both mother and fetus.

Among 69 patients having high risk conditions, where good foetal heart rate and maternal condition permissible for normal vaginal delivery were there; successful vaginal delivery was done due to availability of OBS HDU/ICU for effective management of various postpartum complications. $15 \%$ of cases were referred for previous caesarean section in Khatoon et al Charu et al noted that a majority of the cases were referred for preeclampsia (26\%). ${ }^{9,12}$ Lack of proper infrastructure of OT's and blood banks, Availability of specialized anesthesiologist, neonatologist at periphery is the major 
cause of such referrals. COVID-19 positive patients need invasive/noninvasive oxygen therapy as well as higher level of care and treatment which may not be available at the periphery level and hence were referred to the government hospitals. Also, excessive financial burden in private hospitals is also a driving factor for referrals to government hospitals.

Intraoperative as well as post operative difficulties were taken into consideration. Difficulty in delivery of the baby was encountered in $53 \%$ of cases due to deep engagement of the fetal head. This was seen in patients who were referred very late or after a prolonged trial of labor. Thus, quick assessment and early referrals of such patients will prevent maternal as well as fetal morbidity. Patients having hypertensive disorders of pregnancy had more bleeding as compared to other patients. Difficult delivery of head leading to more manipulation also caused excessive bleeding. Post operatively fever was observed in $12 \%$ of cases. Major cause of maternal mortality in referred cases was hypertensive disorders of pregnancy followed by severe anemia were impending signs of eclampsia and early detection of hypertension was ignored leading to increase in severity of the symptoms. Post COVID-19 infection complications also contributed to maternal morbidity and mortality.

Total live births in this study were 278(99\%) in which 88 babies were admitted in NICU. Poornima et al reported $90 \%$ live births. ${ }^{10}$ Major cause of admission in NICU was sepsis $(38.6 \%)$ followed by prematurity $(23.8 \%)$. Birth asphyxia was observed in neonates where difficult delivery of fetus was noted leading to increase stress on the neonate.Maternal conditions like impending eclampsia, COVID-19 infection worsening the maternal outcome, APH makes it imperative for delivery of baby by caesarean section even if the neonate was premature.

\section{CONCLUSION}

Referral is a coordinated movement of healthcare seekers through the health system to reach a high level of care in a small and often fatal window of time. Complications and risks can arise at any stage of pregnancy which to be dealt with utmost level of care and timely decisions needs need to be taken. Timeliness and appropriateness of referral are a challenge to obstetricians, since delay in referral affects maternal and fetal health adversely. Thus, early detection of high-risk patients and early referrals are of utmost importance.

As observed from this study as well as other studies, Timely intervention by cesarean section reduces the feal and maternal morbidity and mortality to a large extent. Cesarean section is one of the quickest and most efficient method in the delivery of the baby and thus should in considered in patients in critical situations needing immediate intervention. The millennium development goal defined by united nation includes one goal (MDG 5) towards improving maternal health which still remains a challenge. Thus, improving knowledge of women regarding good antenatal care and strengthening referral services will play a big role in this. Good quality health care is a right of every woman and thus updating our maternal and fetal health care is in absolute need.

\section{Funding: No funding sources}

Conflict of interest: None declared

Ethical approval: The study was approved by the Institutional Ethics Committee

\section{REFERENCES}

1. Mahendra G, Kavya BS, Pukale R. S.Study of maternal and perinatal outcome in referredobstetric cases. Obs Rev J Obstet Gynecol. 2019;5(2):106-11.

2. Thaddeus S, Maine D. Too far to walk: maternal mortality in context. Soc Sci Med. 1994;38:1091110.

3. Travis P, Bennett S, Haines A, Pang T, Bhutta Z, Hyder AA, et al. Overcoming health systems constraints to achieve the millennium development goals. Lancet. 2004;364:900.

4. Paxton A, Bailey P, Lobis S. The United Nations process indicators for emergency obstetric care: reflections based on a decade of experience. Int $\mathbf{J}$ Gynecol Obstet. 2006;95:192-208.

5. Morsheda B, Shamsun N, Hashima EN. Assessing the MANOSHI referral system addressing delays in seeking emergency obstetric care in Dhaka's slums. Available at: https://www.semanticscholar.org/ paper/Assessing-the-MANOSHI-Referral-SystemAddressing-in-Banu-Nahar/91fb8ac2f103a52fd35e5 491c1990cfb010eec9c. Accessed on 20 August 2020.

6. Patel HC, Singh BB, Moitra M, Kantharia SL. Obstetric Referrals: Scenario at a Primary Health Centre in Gujarat. Natl J Community Med. 2012; 3(4):711-4.

7. Sharma CP, Sharma S, Kumar A, Jain K.A study to assess genuineness of obstetrics/gynaecological patients coming or being referred to medical college hospital in southern district Rajasthan. Natl J Community Med. 2013;4(1):172-4.

8. Goswami D, Makhija A. A study of high risk obstretic referrals to tertiary care hospital in Garhwal, Uttarakhand. IJSR. 2015;4(10):1091-5

9. Khatoon A, Hansy SF, Irshad S, Ansari J, An audit of obstetric referrals to Abbasi Shaheed Hospital. Pak J Surg. 2011;27(4): 304-8.

10. Poornima M, Rekha G Daver. Maternal and fetal outcome in obstetric referred cases. Glob $\mathrm{J}$ Res Analys. 2018;7(2):544-7.

11. Gupta PR, Chaudhary SN, Gonnade NV. Maternal and fetal outcome in referred patients to tertiary care center. Sch J App Med Sci. 2016;4(5C):1624-63.

12. Charu R, Kamal G, Neelu S. Review of referred obstetric cases-Maternal and Perinatal Outcome. Bombay Hospital J. 2010;52(1):53.

13. Rao RS, Caleb L, Khan ME, Townsend JW. Safer maternal health in rural Uttar Pradesh: Do primary 
health services contribute? Health Policy and Planning. 2001:16;256-63.

14. Sabale U, Patankar AM. A study of maternal and perinatal outcome in referred obstetrics cases. J Evol Med Dent Sci. 2015;4(26):4448-55.

15. Park K. Textbook of preventive and social medicine 17th ed. India: Banarasidas Bhanoj Publishers; 2000:632.
Cite this article as: Shah D, Patel A, Mandaliya M. A study of caesarean sections in referred cases. Int J Reprod Contracept Obstet Gynecol 2022;11:148-52. 